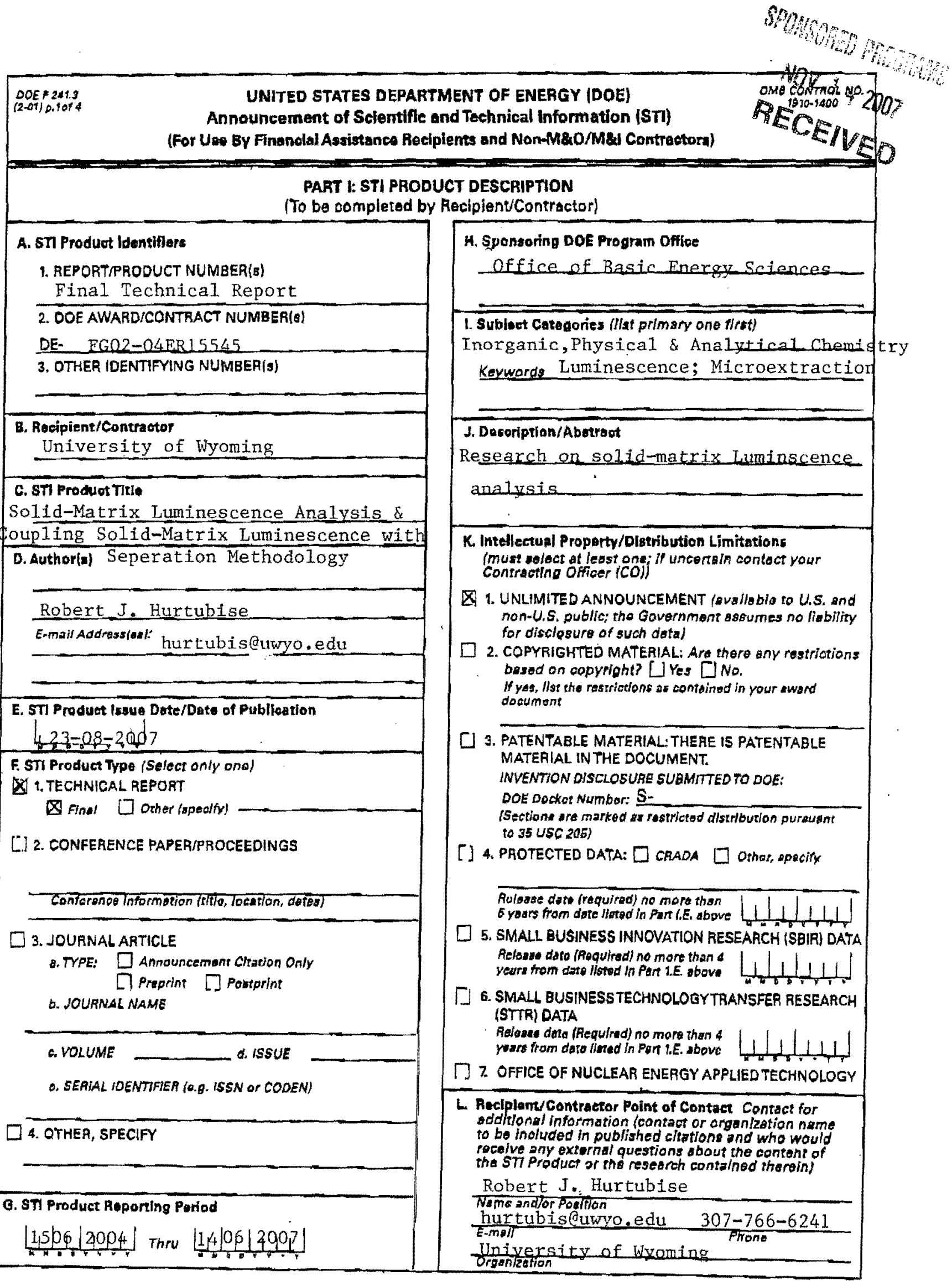




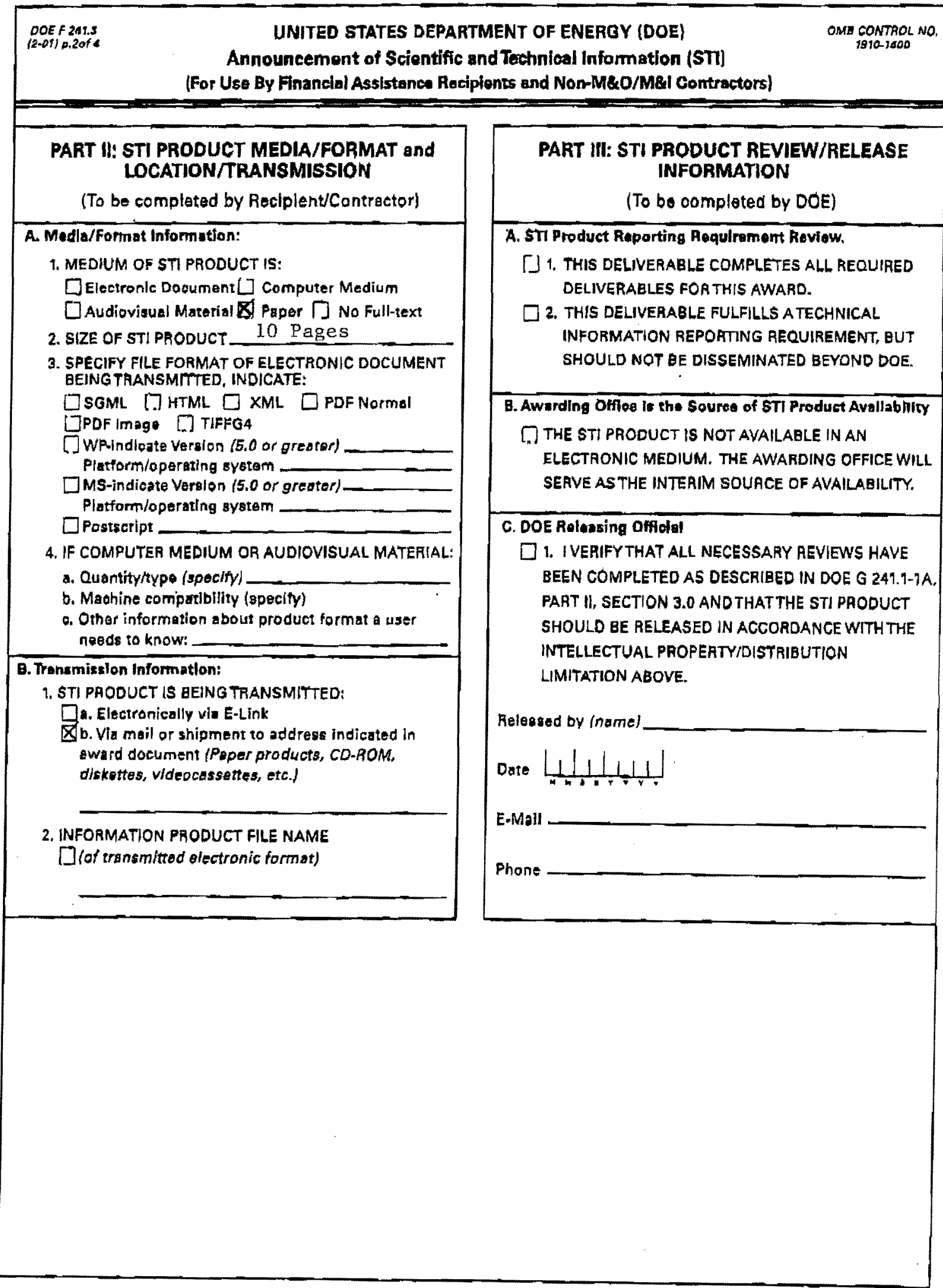


DOE/ER15545

\title{
SOLID-MATRIX LUMINESCENCE ANALYSIS AND COUPLING SOLID- MATRIX LUMINESCENCE WITH SEPARATION METHODOLOGY
}

\author{
Final Peport
}

Period of Grant: 15 June 04-14 June 05

No Cost Extension: 15 June 05 - 14 June 06

No Cost Extension: 15 June 06-14 June 07

Robert J. Hurtubise

Chemistry Department

University of Wyoming

Laramie, WY $82071-3838$

Prepared for the U.S. Department of Energy

Agreement No. DE-FG02-04ER15545

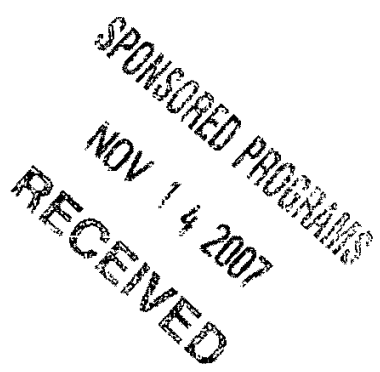




\section{TABLE OF CONTENTS}

Summary

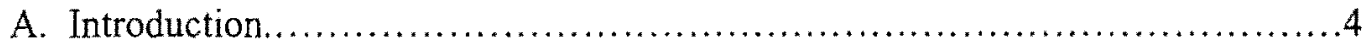

B. Research Papers Published after the Renewal Report for

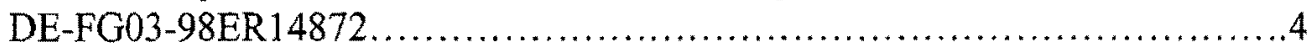

C. Mass Distribution for the Microextraction of Polycyclic Aromatic Hydrocarbon Metabolites...............................................4

D. Solid-Matrix Luminescence of Heterocyclic Aromatic Amines in Several New Sugar-Glass Systems...................................... 5

E. Solid-Matrix Phosphorescence of $( \pm)$-anti-Dibenzo[a,l]pyrene Diol Epoxide-DNA Adducts and Benzo[e]pyrene..............................6 6

E. The Characterization of $( \pm)$-anti-Benzo[a]pyrene Diolepoxide-DNA Adducts and $( \pm$ )anti-Dibenzo[a,1]pyrene-DNA Adducts in the Same DNA Sample Using Solid-Matrix Phosphorescence.

F. The Characterization of ( \pm )-anti-Benzo[a]pyrene Diolepoxide-DNA Adducts and $( \pm)$-anti-Dibenzo[ $a, 1]$ pyrene-DNA Adducts in the Same DNA Sample Using Solid-Matrix Phosphorescence

G. Characterization of Placental DNA Samples by Room-Temperature Solid-Matrix Phosphorescence for Polycyclic Aromatic Hydrocarbon-DNA Adducts...

References. 


\section{Summary}

The research papers published after the renewal Report for DE-FG03-98ER14872 was submitted to DOE are listed as references 1-3. With the one year of funding provided by DOE (DE-FG02-04ER15545) and the two no-cost extensions, most of the work not completed under DOE/ER14872 was finalized. Some of the research under DOE/ER14872 and DOE/ER15545 was also funded by both DOE and NIH.

Mass distribution data were obtained for 2-naphthol and three polycyclic aromatic hydrocarbon (PAH) metabolites in a liquid-liquid-liquid microextraction microfiber. These data permit various distribution constants to be calculated for the microextraction system and thus aid in understanding how the solutes distribute in the three phases. Several new sugar glasses were introduced and their potential was investigated for obtaining solid-matrix fluorescence SMF) and solid-matrix phosphorescence (SMP) from phosphors. General guidelines such a glass transition temperature and solubility were developed for selecting a sugar glass for SMF and SMP.

The first solid-matrix phosphorescence (SMP) photophysical data were obtained for $( \pm)$-anti-dibenzo[a,1]pyrene diol epoxide-DNA adducts. These adducts result from the metabolism of dibenzo[a,l]pyrene. The previous $\mathrm{PAH}$ is most carcinogenic of the PAH. The first SMP photophysical data were acquired for ( \pm )-anti-benzo[a]pyrene diolepoxideDNA adducts and $( \pm)$-anti-dibenzo[a,l]pyrene-DNA adducts in the same DNA sample. The detection and characterization of multiple adducted DNA samples are unexplored areas of research and are very important in cancer and environmental research. SMP methodology was developed for the first time for the direct detection of PAH-DNA adducts in human placental DNA samples. These results open news avenues of research for the direct characterization of multiple adducted PAH-DNA samples. 


\section{A. Introduction}

In this report, the research papers published after the Renewal Progress Report for DE-FG03-98ER14872 (Period of Grant: 15 June 01 - 14 June 04) was submitted are very briefly discussed and the appropriate references to the research papers are listed at the end report. The remainder of the report considers the research accomplished under DE-FG02-04ER15545. The research under ER15545 was funded for one year, but ER15545 was extended for two additional years with no-cost extensions.

\section{B. Research Papers Published after the Renewal Report for DE-FG03-}

\section{ER14872 Was Submitted to DOE}

New solid-matrix methodology was developed for the characterization of ( \pm )-antibenzo[a]pyrene-trans-7,8-dihydrodiol-9,10-epoxide[BPDE]-DNA adducts and a hydrolysis product of the DNA adducts, tetrol [-1 [1]. A novel liquid-liquid-liquid microextraction approach was developed for the enrichment of polycyclic aromatic hydrocarbon metabolites [2]. Enrichment factors were determined by fluorescence spectrometry, and a new microextraction method was combined with capillary electrophoresis. The solid-matrix fluorescence (SMF) quenching of benzo[e]pyrene and ( \pm -anti-BPDE-DNA adducts with $\mathrm{TINO}_{3}$ and $\mathrm{NaI}$ was examined and several SMF quenching models were developed [3].

\section{Mass Distribution for the Microextraction of Polycyclic Aromatic}

\section{Hydrocarbon Metabolites}

Mass balance data were acquired using fluorescence spectrometry for 2-naphthol and three polycyclic aromatic hydrocarbon (PAH) metabolites using liquid-liquid-liquidmicroextraction and liquid-liquid-microextraction systems. The PAH metabolites are 
very important biomarkers in cancer research, and there has been no previously reported mass balance data on these compounds with microextraction systems. In addition, the effects of two solvent systems used in the preparation of donor and acceptor phases were investigated. The effects of the solvent systems on the partitioning process were compared. The mass-balance results showed that significant amounts of the hydrophobic metabolites were held in the pores of the microfiber in both the three-phase and two-

phase microextraction systems. Based on the mass-balance data, a new enrichment factor was defined as the concentration of the solute trapped in the pores of the fiber divided by the initial concentration of the solute in the donor phase. Because of the relatively large amount of the solute in the pores, it is envisioned that the solutes could be easily extracted from the pores, the extraction solvent concentrated, and the components further separated by capillary electrophoresis or characterized by solid-matrix phosphorescence, solution fluorescence, or mass spectrometry [4].

\section{Solid-Matrix Luminescence of Heterocyclic Aromatic Amines in Several New}

\section{$\underline{\text { Sugar-Glass Systems }}$}

Several new sugar glasses were investigated for their potential in solid-matrix luminescence. Both solid-matrix fluorescence (SMF) and solid-matrix phosphorescence (SMP) properties were obtained, and two heterocyclic aromatic amines were employed as model compounds. In addition to glucose glasses, which were investigated previously, fructose, ribose, xylose, galactose, maltose, and glucose with poly(acrylic acid) (PAA) were studied. Detailed experimental conditions were obtained for each sugar-glass system. In addition, $\mathrm{NaI}$ was investigated as a heavy-atom salt in the sugar-glass systems to enhance the SMP of the heterocyclic aromatic amines. The SMF intensity was the 
strongest in maltose and glucose with PAA for 2-amino-1-methyl-6-phenylimidazo[4,5-

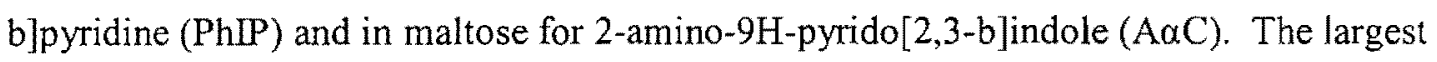
SMP signals for PhIP with and without NaI were acquired in glucose with PAA. For AaC with NaI, the strongest SMP signal was obtained in maltose. Limits of detection were obtained for PhIP in of the several sugar-glass systems, and the lowest limit of detection was $0.04 \mathrm{pmol} / \mathrm{mg}$ of PhIP in maltose with NaI present. An extensive study was carried out using both SMF and SMP to determine if neutral and/or protonated species of PhIP and $\mathrm{A} \alpha \mathrm{C}$ were in the sugar-glass systems. General guidelines, such as glass transition temperature and solubility, were developed for selecting a sugar glass as a solid matrix [5]. In related work, the heat capacities of several glucose glasses, with and without $\mathrm{NaI}$, were obtained over a wide range of temperatures. The heat capacities of the sugar glasses will be correlated with photophysical parameters of a phosphor in the glasses. The correlations will give a better understanding of the nonradiative deactivation of phosphors in sugar glasses [6].

\section{E. Solid-Matrix Phosphorescence of $( \pm)$-anti-Dibenzo]a,llpyrene Diol Epoxide-}

\section{DNA Adducts and Benzo[elpyrene}

This part of the research was funded by DE-FG02-04ER15545 and NIH (R03CA97723). New solid-matrix phosphorescence (SMP) methods for ( \pm )-anti$\mathrm{DB}[\mathrm{a}, 1] \mathrm{PDE}-\mathrm{DNA}$ adducts and $\mathrm{B}[\mathrm{e}] \mathrm{P}$ were developed. The methods can be used to detect and characterize $( \pm$ )-anti-DB[a,1]PDE-DNA adducts and $\mathrm{B}[\mathrm{e}] \mathrm{P}$ by employing SMP spectra, intensities, and lifetimes with the heavy-atom salt, $\mathrm{TINO}_{3}$, on Whatman 1PS paper. With the SMP data, a number of photophysical parameters were calculated such as bi-exponential SMP decay curves, pre-exponential factors, and fractional contribution 
to SMP decay curves. The SMP results were compared with earlier SMP data for ( \pm )anti-BPDE-DNA adducts and tetrol I-1. The SMP results show that small molecularweight compounds like B[e]P can be readily detected and characterized by SMP. For example, the limit of detection for $\mathrm{B}[\mathrm{e}] \mathrm{P}$ was 0.60 pmole. Comparison of the SMP properties of the $( \pm)$-anti-DB[a,1]PDE-DNA adducts with earlier SMP data for the $( \pm)$ anti-BPDE-DNA adducts showed major differences in the SMP spectra, intensities, and lifetimes. The methods developed are important for the comparison of the SMP properties of different diol epoxides of PAH bonded to DNA [7].

\section{F. The Characterization of ( \pm )-anti-Benzola]pyrene Diolepoxide-DNA Adducts} and ( \pm )-anti-Dibenzo[a,llpyrene-DNA Adducts in the Same DNA Sample Using

\section{Solid-Matrix Phosphorescence}

This portion of the research was funded by DE-FG02-04ER15545 and NIH (R03CA97723). Solid-matrix phosphorescence (SMP) spectra and lifetimes were used to characterize the $( \pm)$-anti-benzo[a]pyrene diolepoxide $[( \pm)$-anti-B[a]PDE] and $( \pm)$-antidibenzo[a,l]pyrene diolepoxide $[( \pm)$-anti-DB[a,l]PDE] bonded to the same sample of DNA. SMP spectra and lifetimes were also acquired for two samples of DNA that had only ( \pm -anti-B[a]PDE or ( \pm -anti-DB[a,1]PDE bonded to the individual samples of DNA. A detailed comparison of the SMP properties was made among the three samples of DNA. The SMP excitation spectra for the ( $( \pm)$-anti-B[a]PDE-DNA and the ( \pm )-antiDB[a,1]PDE-DNA adducts were very similar. However, the SMP emission spectra of the two DNA adduct systems were very dissimilar with a major emission band for the $( \pm)$ anti-B[a]PDE-DNA adducts appearing at $613 \mathrm{~nm}$ and for the ( \pm -anti-DB[a,1]PDE-DNA adducts a major band was at $558 \mathrm{~nm}$. It was possible to selectively use SMP emission 
wavelengths and obtain a SMP excitation of spectrum of the ( \pm )-anti-DB[a,1]PDE-DNA adducts in the dual adducted DNA sample without the $( \pm)$-anti-B[a]PDE-DNA adducts emitting SMP. In addition, it was shown that the SMP emission spectrum of the dual adducted DNA sample could be used to detect both adduct systems in the modified DNA sample. It was demonstrated that the SMP lifetimes could be effectively employed to characterize the dual adducted DNA sample. For example, the SMP decay curve for the $( \pm)$-anti-DB[a,1]PDE-DNA adducts could be acquired without any SMP emission from the $( \pm$ )-anti-B[a]PDE-DNA adducts. Also, In (SMP intensity) versus time plots were very useful in characterizing the dual adducted DNA sample [8].

\section{G. Characterization of Placental DNA Samples by Room-Temperature Solid-} Matrix Phosphorescence for Polycyclic Aromatic Hydrocarbon-DNA Adducts

This portion of the research was funded by DE-FG02-04ER 15545 and NIH (R03CA97723). Little work has been done on the intact detection of polycyclic aromatic hydrocarbons (PAH)-DNA adducts. In this work, we give the first results of the direct detection of PAH-DNA adducts in human placental DNA samples by solid-matrix phosphorescence (SMP). A heavy-atom salt $\left(\mathrm{TINO}_{3}\right)$ was used to enhance the SMP. Six samples were investigated, and PAH-DNA adducts were detected in most of the samples by their SMP emission spectra and the corresponding second derivative SMP spectra. Both excitation and emission spectra were investigated. However, because of limited sample quantities and less potential interference, emphasis was placed on acquiring SMP emission spectra. Several excitation and emission wavelengths were studied for detecting the PAH-DNA adducts in the placental DNA samples. In addition, second derivative SMP excitation and emission spectra were very effective in detecting the PAH-DNA 
adducts. The SMP properties of unmodified calf-thymus DNA were also studied in detail and compared to the SMP properties of the placental DNA samples. The SMP of calfthymus DNA was enhanced in the presence of $\mathrm{TINO}_{3}$, and the SMP of the calf-thymus DNA emitted in the same region as some PAH aromatic ring systems. However, the longer SMP emission region proved to be fruitful for detecting PAH-DNA adducts in the placental DNA samples. The results for the placental samples indicated that a variety of PAH-DNA adducts were present in the placental samples [9].

\section{REFERENCES}

1. Smith, B. W.; Hurtubise, R. J. Anal. Chim. Acta 2004, 502, 149-159, "New Methodology for the Characterization of ( \pm )-anti-BPDE-DNA Adducts and Tetrol I-1 with Solid-Matrix Phosphorescence."

2. Marlow, M; Hurtubise, R. J. Anal. Chim. Acta 2004, 526, 41-49, "Liquid-LiquidLiquid Microextraction for the Enrichment of Polycyclic Aromatic Hydrocarbon Metabolites Investigated with Fluorescence Spectroscopy and Capillary Electrophoresis."

3. Thompson, A. L.; Hurtubise, R. J. Appl. Spectrosc. 2005, 59, 126-133, "Solid-Matrix Fluorescence Quenching of Benzo[e]pyrene and $( \pm)$-anti-Benzo[a]pyrene DiolepoxideDNA Adducts."

4. Marlow, M.; Hurtubise, R. J. Talanta 2006, 69, 443-449, "Mass Distribution for the Microextraction of Polycyclic Aromatic Hydrocarbon Metabolites Investigated with Fluorescence Spectrometry."

5. Hubbard, S. E.; Hurtubise, R. J. Talanta 2007, 72, 132-139, "Solid-Matrix Luminescence of Heterocyclic Aromatic Amines in Several New Sugar-Glass Systems."

6. Hubbard, S. E.; Hurtubise, R. J. Appl. Spectrosc., in preparation, "Relationship between the Heat Capacity of Sugars and the Solid-Matrix Phosphorescence of Phosphors."

7. Thompson, A. L.; Hurtubise, R. J. Anal. Chim. Acta 2006, 560, 134-142, "The SolidMatrix Phosphorescence of $( \pm)$-anti-Dibenzo[a,1]pyrene Diol Epoxide-DNA Adducts and Benzo[e]pyrene." 
8. Thompson, A. L.; Hurtubise, R. J. Anal. Chim. Acta 2007, 584, 28-36, "The Characterization of $( \pm)$-anti-Benzo[a]pyrene Diolepoxide-DNA Adducts and $( \pm)$-antiDibenzo[a,1]pyrene-DNA Adducts in the Same DNA Sample Using Solid-Matrix Phosphorescence."

9. Hurtubise, R. J.; Thompson, A. L.; Weston, A.; Manchester, D. K. Anal. Chim. Acta, in preparation, "Characterization of Placental DNA Samples by Room-Temperature Solid-Matrix Phosphorescence for Polycyclic Aromatic Hydrocarbon-DNA Adducts." 